\title{
Stress and Coping Mechanisms: A Historical Overview
}

\section{Dr. Shadiya Mohamed Saleh Baqutayan}

Perdana School of Science, Technology and Innovation Policy, University technology Malaysia, Kuala Lumpur Campus

\section{Doi:10.5901/mjss.2015.v6n2s1p479}

\author{
Email: shadiya.kl@utm.my
}

\section{Abstract}

Stress is not new experience to all of us, it's seen as modern society's illness, as most people, no matter how well adjusted, will suffer at least short-term distress while they negotiate periods of transition, trauma, challenges and loss. Stress has great impact on one performance and efficiency; however, the intense pressure and the demands of coping determine the consequence of stress on performance. Therefore, this paper discusses on the relationship between stress and coping mechanisms. The purpose of this study is twofold: to understand the history of stress related problems, and to provide suitable model that brings all ways of coping mechanism into one. Eventually, the important variables or factors associated with stress, and their direct or indirect effects on various outcome measures such as mental health, physical health, and performance will be taken into account. The result and the explanations of this literature might help everyone to find out the main reason for their stressors, best way to cope and greatest technique to use in managing stress.

Keyword: Stress Management; Stress And Coping Mechanisms; From the History of Stress; History of Coping

\section{Introduction}

This study was based on a theory of psychological stress and coping developed by Lazarus and his colleagues over a number of years (Folkman \& Lazarus, 1985), and then expanded by Carver and colleagues in 1989. The theory identifies the process of coping as critical mediators of stressful person-environment relations and their immediate and long-range outcomes. No doubt, in the first place, psychologist has defined stress as an unpleasant state of emotional and physiological arousal that people experience in situations that they perceive as dangerous or threatening to their wellbeing. And coping as the cognitive and behavioral efforts to master, reduce, or tolerate those demands (Folkman \& Lazarus, 1980). But due to the differences between researchers in how stress was defined, and how coping with it was different, this research tries to provide a full understanding and more detail about the meaning of stress, strain and coping mechanisms from the past literatures.

\section{Background}

Hans Selye firstly introduced the term "stress" into the health psychology language in 1926. Although the term "stress" is a household word, Selye actually used the descriptive term "strain" to denote his concept, since it suggested structural changes whereas stress emphasized external factors. To him "stress" consisted of the "sum of all nonspecific changes (within an organism) caused by function or damage" or, more simply "the rate of wear and tear in the body" (Selye, 1956).

Then, from Hans Selye's starting point, researchers used the term "stress" in the index of psychological abstracts in 1944 (Lazarus and Folkman, 1984). Some writers, like Pollock in 1988, argued that the use of the term "stress" is relatively recent. But she suggested that although it was used to some extent throughout the 19th century and was loosely associated with ill health, it is only in the last few decades that it has really become an established term. Newton (1995), however, disagreed that the term is of recent origin, having found definitions of stress in the Oxford English Dictionary, which are very close to our present understanding of the term, dating back to the 16th and 17th century. Nevertheless, there seems to be a general consensus that popularity of the concept gained ground from the Second World War on wards (Kugelmann, 1992; Newton, 1995).

It is true that everyone is talking about stress, but usually when they talk, they use the term of pressure they are feeling from something happening around them or to them. For example, students talk about being under stress because of poor exam performance or an impending deadline for a major paper. Parents talk about the strain of raising teenagers and the financial burdens of running a household. Teachers talk about the pressure of maintaining professional currency and research while still managing to keep up with teaching and advising. Doctors, nurses, and lawyers talk about meeting the endless demands of their patients and clients (Rice, 1999). But what is the exact meaning of the word "stress"?

Stress is something that all of us experience from time to time but have difficulty defining it. If people were asked to talk about it, they tend to describe how it feels to them or what it makes them do, but they can hardly ever say what it is. According to Hans Selye, the prolific writer on the topic of stress over the last 50 years, that stress is the non-specific response of the body to any demand made upon it (Selye, 1973). By this, there is a common response to different types 
of stressors, and he named this set of responses the general adaptation syndrome (GAS). The term non-specific refers to the fact that a wide variety of demands or stressors bring forth a common response. He identified three stages in the GAS each associated with changes in nervous and endocrine functioning: the alarm reaction, the stage of resistance and the stage of exhaustion (Jones \& Bright, 2001).

Gradually, the growth of the study of psychology has led to a proliferation of definitions, which has not necessarily helped to clarify the meaning of the term. Over 20 years ago, Kasl (1978) listed a range of conceptualizations, from the highly specific to the extremely general, encompassing both stimulus and response. For example, stress was sometimes conceptualized in terms of environmental conditions which were considered stressful (Landy \& Trumbo, 1976), or in terms of 'frustration or threat' (Bonner, 1967) or more advanced conceptualizations incorporating the stimuli and response and the relationship between the two. Here Kasl cites the popular definition by McGrath (1976) who suggested that stress was a (perceived) substantial imbalance between demand and response capability, under conditions where failure to meet demand has important (perceived) consequences. This diversity of conceptualizations has persisted over the years.

Still, much confusion exists about the meaning of stress. This confusion is because some stressors can motivate, stimulate and push people beyond the limits of what they believe themselves capable. But the symptoms and harmful effects of stress have been emphasized so frequently that the word itself now connotes little short of illness, a disease, something to be rigorously avoided.

Most people see stress as a bad thing but we can all use a bit of stress now and then. According to Smith (1990), stress makes us do things at times when we need a push; it gets us out of our chair; it makes us think about things differently; it makes us seek solutions to problems; and it sometimes makes us sensitive to what others may think of us and our actions. In addition to that, many people use stress and distress as though they are interchangeable terms. Perhaps this is because common sense suggests that stress is something bad.

To avoid this dilemma, Hans Selye introduced the term's "distress" and "eustress". According to Selye (1974), distress is damaging or unpleasant stress. Expressed in these terms, stress is much the same as a state of anxiety, fear, worry, or agitation. The core of the psychological experience is negative, painful, something to be avoided. Pleasurable, satisfying experiences come from what Selye (1974) calls eustress. Participating in a wedding ceremony, anticipating competition in a major sport event, and performing in a theatrical producing are examples of eustress. This is positive stress. We even hear of the "joy of stress" a phrase some use to emphasize the good that can come from stress (Hanson, 1986). So is stress healthful or injurious? This can be answered through the definition of stress.

The word stress means different things to different people. Some people define stress as events or situations that cause them to feel tension, pressure, or negative emotions such as anxiety and anger. Others view stress as the response to these situations. This response includes physiological changes-such as increased heart rate and muscle tension-as well as emotional and behavioral changes. However, most psychologists regard stress as a process involving a person's interpretation and response to a threatening event (Microsoft Corporation 2000).

Mills (1982) defined stress as our inner reaction to things that happen to us and demands that are placed on us. We all experience stress when we are anxious, worried, shamed, or angry, whether the source of our feeling is ourselves, some other person, or something that happens to us. We can deal with stress adequately only when we consider both components of stress: the external events and demands in our lives and our inner reaction to them. Sandhu et al. (1994) defined stress as the adaptive physiological response of the human organism to internal and external force and events that disturb the homeostatic balance of the individual. Psychological stress occurs as results of a person perceiving environmental demand exceeding coping abilities.

Buck (1972) defined stress as the work of environment; according to him environment is perhaps most often central in the experience of stress among adults. Swent \& Gmelch (1977) found that $75 \%$ of the stress educational administrators felt come from their jobs. Conditions of one's job and events related to work, then, become critical components of the stress syndrome. Cooper \& Marshall (1976) determined that professionals involved in interaction with other people were more vulnerable to work- related stress than workers in product-oriented organizations were. Studies of police, administrators, teachers, students, and others verify this fact. Benjamir \& Walz (1990) conclude that stress can best be understood as the product of interaction between three elements: the environment (the organizational or social climate, interpersonal relationships, operating procedures), the nature of the stressor (nagging, daily pressures or lifethreatening events), and the individual's vulnerability to stress (difference to coping styles, support groups, health history values).

In contemporary scientific literature, stress has three distinct meanings. First, it may refer to any event or environmental stimulus that causes a person to feel tense or aroused. In this sense, stress is something external. Second, stress may refer to a subjective response. In this sense, stress is the internal mental state of tension or arousal. It is the interpretive, emotive, defensive, and coping processes occurring inside a person. Such processes may promote 
growth and maturity. They also may produce mental strain. Finally, stress may be the body's physical reaction to demand or damaging intrusions. The function of these physical reactions is probably to support behavioral and psychological efforts at coping (Baum, 1990).

According to Jones and Bright (2001), some writers disagree with the idea that there is disagreement about the concept of stress. For example, Cox (1993) criticizes the 'unfortunate but popular misconception that there is little consensus on the definitions of stress as a scientific concept or, worse, that stress is in some way indefinable and immeasurable'. However, the definition he offers suggests that the goal of a clear conceptualization remains as elusive as ever. He states that 'stress can be defined as a psychological state which is part of and reflects a wider process of interaction between individuals and their work environment '(Cox, 1993, p. 29).

The term 'stress' is so vague in definition that it has been suggested that perhaps the most useful approach to stress would be to regard it not as a variable but as a 'rubric consisting of many variables and processes'. In addition to that, researchers should adopt a systematic theoretical framework encompassing relevant antecedents, processes and outcomes (Lazarus and Folkman, 1984).

One person's stress may well be another's pleasure. According to Kenneth et al. (1997), one useful definition of stress describes it as our psychological and physiological reactions to a situation perceived as exceeding our coping resources. Many psychologists distinguish between the situation (the "stress") and our resulting response ("distress"), recognizing that it is the latter that is likely to be detrimental to health and well-being. How negatively we react to stress depends on a number of factors, including how much control we feel over the situation, how predictable and intense the stressor is, and our individual perspective. For example, the hustle and bustle of a crowded city street may be sweet music to one driver and unbearable to another.

To be clearer about the concept of stress, you have to know the sources of stress (stressors), so that you can relate stress to its sources. Indeed, many psychologists talked about it, and one of them is Carlesworth, while the other is Nathan. In 1982, Carlesworth \& Nathan defined stressors as the external demands of life or the internal attitude and thoughts that require us to adopt. Stressors can include traffic jams, pollution in the city, the fifth cup of coffee, the pushy salesman who will not take no for an answer, or the angry boss. Stressors can also include the work that never seems to get done, the children who never seem to listen, or the way some people put themselves down for their shortcomings. Notice that some of these stressors come from our surrounding and others from our inner struggles. Some stressors come from both sources.

Individuals cannot remain in a continuous state of tension and emotional strain. Even if a deliberate and conscious strategy is not adopted to deal with stress, some strategy is adopted; for example, to leave the conflicts and stress to take care of themselves. The concepts of stress and coping are neutral. Although people commonly see stress as negative and coping as positive, the relationship is not that simple. Stress can be psychologically positive or negative, and the means of coping can be effective or ineffective in meeting the challenge presented by the stressful situation.

In one early attempt to define coping, Folkman and Lazarus (1980) suggested that coping is all the cognitive and behavioral efforts to master, reduce, or tolerate demands. It makes no difference whether the demands are imposed from the outside (by family, friend, job, school, for example) or from inside (while wrestling with an emotional conflict or setting impossibly high standards, for example). Coping seeks in some way to soften the impact of demands.

Kenneth Matheny and his coworkers reviewed a large body of coping research and arrived at a similar definition (Matheny, Aycok, Pugh,Curlette, and Silva-Cannella, 1986). They defined coping as "any effort, healthy or unhealthy, conscious or unconscious, to prevent, eliminate, or weaken stressors, or to tolerate their effects in the least hurtful manner". One aspect of this definition deserves comment that is coping efforts are not always healthy and constructive. People sometimes adopt coping strategies that actually get them into more difficulty. One example is the person who embezzles money to solve personal financial problems. Coping efforts may have a positive goal, but the out come of faulty coping may be anything but positive.

Psychologists (e.g., Pestonjee, 1992) have identified two major ways in which people cope with stress. In the first approach, a person may decide to suffer or deny the experienced stress; this is the passive approach. Alternatively, a person may decide to face the realities of the experienced stress and clarify the problem through negotiations with other members. This is the active approach.

Researchers have grouped the ways people cope with stress into four categories. First, they may decide to fight the realities of experienced stress; they try to struggle in order to achieve what they want. Second, they may decide to flight or leave what make them feel stressed. Third, they may reduce their stress through such activities like social support, and religious orientation. Finally, they may decide to accept their life as it is. The main question is that, which one of these four categories is applicable to cope with academic stress.

Lazarus and Folkman concentrate on two types of coping strategies: problem-focused coping and emotion-focused 
coping. In the problem-focused coping, efforts are made to change the stressful situations through problem solving, decision-making and/or direct action. In emotion-focused coping, attempts are made to regulate distressing emotion, sometimes by changing the meaning of the stressful situation cognitively without actually changing the situation (Folkman \& Lazarus, 1985).

Recent study done by Sacchi (2000) indicated that coping includes behavior and thoughts employed by the individual to manage the stressing situation. Moreover, according to him, Folkman and Lazarus' theory defines two coping principles: the first category, problem focused coping, refers to strategies employed to alter or manage source of stress. The second category, emotion focused coping, has to do with the strategies used to manage emotions.

Distinction between these two general types of coping, Lazarus and Folkman (1989) explained them in detail. According to them, problem-focused coping is aimed at problem solving or doing something to alter the source of the stress. Whereas emotion-focused coping is aimed at reducing or managing the emotional distress that is associated with the situation. Eventually, and since this study focuses on the historical perspective of stress and coping, it aims to structure a good model for stress and coping that brings all ways of coping mechanism into one.

\section{Theoretical Frameworks}

The method used by Lazarus and Folkman was based on specific efforts, both behavioral and psychological, that people employ to master, tolerate, reduce, or minimize stressful events. Their method was very clear; they had distinguished between the two general coping strategies: problem-solving strategies are efforts to do something active to alleviate stressful circumstances, whereas emotion-focused coping strategies involve efforts to regulate the emotional consequences of stressful or potentially stressful events. Therefore, researcher concludes that coping has two major functions: dealing with the problem that is causing the distress (problem-focused coping) and regulating emotion (emotion-focused coping).

Obviously, Problem-focused coping is the use of specific activities getting the task accomplished, whereas emotion-focused coping is the use of activities to feel better about the task. If the students applied for instant the method of problem-focused coping for a task that was beyond their accomplishment, they would only frustrate themselves and become distressed. Given such an impossible task, they would do better to joke about it, or discuss their feelings with a friend. Conversely, if a task can be accomplished but they are uncertain by joking and partying with friends, they are employing emotion-focus coping when they should have engaged in activities to get the task done.

According to Lazarus and Folkman, problem focused coping include confrontative Coping, Seeking Social Support, Plan full Problem-Solving, and Seeking Social Support. Whereas, emotion focused coping includes Self-Control, Seeking Social Support, Distancing, Positive Appraisal, Accepting Responsibility, and Escape/Avoidance.

Table 3.1. Ways of Coping Mechanisms used by (Lazarus, et al. 1986)

\begin{tabular}{ll}
\hline Problem focused coping: & Emotion focused coping: \\
\hline -Confrontative Coping & -Self-Control \\
-Seeking Social Support & -Seeking Social Support \\
-Plan full Problem-Solving & -Distancing \\
& - Positive Appraisal \\
& -Accepting Responsibility \\
& -Escape/Avoidance \\
\hline
\end{tabular}

Moreover, according to Carver and Weintraub (1989), problem-focused coping include active coping, planning, restraint coping, seeking social support for instrumental reasons, and suppression of competing activities; whereas emotionfocused coping are positive reinterpretation and growth, religion, humor, acceptance, and seeking social support for emotional reasons. Moreover, he added one more model named dysfunctional coping, which contents focus on, and venting of emotions, denial, behavioral disengagement, mental disengagement, and alcohol/drug use. Carver et al. reported alpha reliabilities all above (0.6) except for the mental disengagement scale (.45).

Table 3.2. Ways of Coping Mechanisms Used by (Carver, et al., 1989)

\begin{tabular}{lll}
\hline Problem-focused coping: & Emotion-focused coping: & Dysfunctional Coping: \\
\hline -Active coping & -Seeking social support for emotional reasons & -Focus on and venting of emotions \\
-Planning & -Positive reinforcement and growth & -Behavioral disengagement \\
-Suppression of competing activities & -Acceptance & -Mental disengagement \\
-Restraint coping & -Turning to religion & -Alcohol-drug use \\
-Seeking social support for instrumental reasons & - Humor & - Denial \\
\hline
\end{tabular}


This literature tried to group both ways of coping mechanisms used by Lazarus and Folkman (emotion-and-problemfocused coping) into one, except that the 15 ways of Carver's distinct activities were supplementary into these two categories of coping mechanisms (Table 3.3).

Table 3.3. Researcher own Usage for Coping Mechanisms in this Study

\begin{tabular}{ll}
\hline Problem focused coping: & Emotion focused coping: \\
\hline -Active coping & -Seeking social support for emotional reasons \\
-Planning & -Positive reinterpretation and growth \\
-Suppression of competing activities & -Acceptance \\
-Restraint coping & -Denial \\
-Seeking social support for instrumental reasons & -Turning to religion \\
- Behavioral disengagement & -Focus on and venting of emotions \\
& - Mental disengagement \\
$*$ Researcher is going to discourage the use of alcohol and drugs. & -Humor
\end{tabular}

Since this paper stressed on the stress and coping: The historical perspective, it focuses on both types of coping mechanism: problem-and emotion-focused coping that aimed as intervention in reducing or managing the stress among people. At the end, researcher tried to find out the best between these two types of coping mechanism as a way to be used for managing stress (Figure 1).

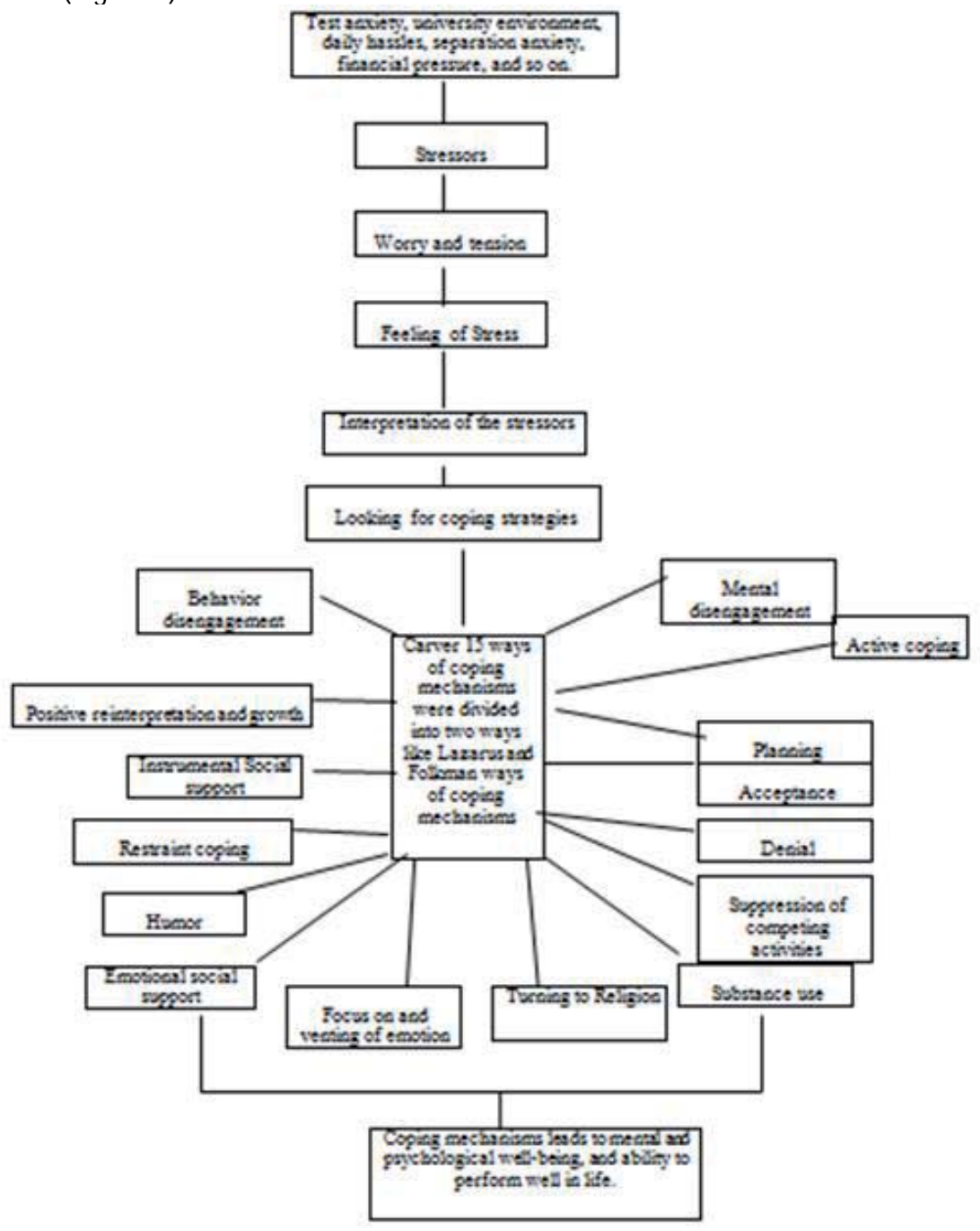

Figure 1: Theoretical Frameworks 


\section{What Does the Term Stress Refer to?}

There is no agreement regarding the derivation of the term "stress." Some sources suggested that the term was derived from the Latin word stringer meaning to "bind tightly." Other sources contend that the term derived from the French word destress (English-distress) and suggested that the prefix "dis" was eventually eliminated because of slurring, as in the case of the word because sometimes becoming cause (Ashforth \& Humphrey, 1993).

Stress is a term that almost everybody from all walks of life knows and uses, yet understanding and assessing stress is a complex task. It is often loosely used to refer to any situation that evokes negative thoughts and feelings in a person. The same situation is not evocative or stressful for all people, and all people do not experience the same negative thoughts and feelings when stressed (Whitman, 1984).

In 1925, Hans Seyle, the European physician trained at the German University in Prague, noticed that all his patients displayed the same symptoms, including fatigue, aching bones and joints, fever, and appetite and weight loss. He subsequently developed the concept of "stress" and the body's adaptive reactions to any demand or "the rate of wearand-tear caused by life." A number of agents can cause stress, including intoxification, trauma, nervous strain, heat, cold, muscular fatigue, polluted air and radiation. According to Seyle, the body reacts to stress in the same way it reacts to danger - by going through a series of biochemical changes, which he called the General Adaptation Syndrome (GAS). In the firs phase, the body mobilizes its defenses against the stressor agent in a "fight or flight" response: the heartbeat is accelerated, blood pressure levels are elevated, an increased amount of blood flows to the muscles, and the lungs dilate to increase respiratory effort. The second phase of GAS is the "resistance phase" during which the body continues to fight the stress long after the effects of the "fight or flight" response have worn off. If infectious agents induce the stress, the body's immune system activity increases; if the stress is physical, the neuroendocrine system converts protein to energy; if the stress is psychological, a combination of responses may occur (Smith, 1999).

Many people may not be aware that they are undergoing stress; few recognize that events such as pregnancy, retirement, marriage, death of a close family member, divorce, and writing exams or a number of smaller events, overload the adaptive system of the body, which causes high levels of stress (smith, 1999).

A common generalized literal description of the term is a "constraining force or influence." When applied to human beings, this could be interpreted to mean the extent to which the body can withstand a given force or influence. In this regard, one of the most often quoted descriptions of stress is that of the Hans Selye (1956), who described it as the "nonspecific response of the body to any demand made upon it."

Selye's definition means that stress involves a mobilization of the bodily resources in response to some sort of stimulus (stressor). These responses can include various physical and chemical changes in the body. Saying that it involves demands that tax and/or exceed the resources of the human body could extend this description of stress. This means that stress not only involves these bodily responses, but that it also involves wear and tear on the body brought about by these responses. In essence, stress can be considered any factor acting internally or externally that makes it difficult to adapt and that induces increased effort on the part of a person to maintain a state of balance within him or her and the external environment. It should be understood that stress is a state that one is in, and this should not be confused with any stimuli that produces such a state (stressor) (Ashforth \& Humphrey, 1993).

McGrath (1970) defined stress as a substantial imbalance between environmental demand and the response capability of the focal organism. Whereas, Kaplan (1983) defined stress as subject's inability to forestall diminish perception, recall, anticipation, imagination of disvalued circumstances, those that in reality or fantasy signify great and/or increased distance from desirable (valued) experiential states, and consequently, evoke a need to approximate the valued states. One could combine Kaplan's and McGrath's definitions of stress and emerge with a rather complete model and definition such as Hobfoll's (1988) definition of stress. He define stress as the state in which individuals judge their response capabilities as unable to meet the threat to the loss of desirable experiential states-states that are directed by their values and expectations.

One model that is useful in understanding stress is the person- environment model. According to one variation of this model, an individual can appraise stressful events as "challenging" or "threatening" (Lazarus, 1966). When people appraise their problem a challenge, stress can bring them a sense of competence and an increased capacity to learn. But when this problem is seen as a threat, however, stress can elicit feelings of helplessness and a foreboding sense of loss.

\section{Coping Mechanism}

In more detail, the term coping refers to the ways that people respond to and interact with problem situations (Zamble \& Gekoski, 1994). Life continuously presents people with circumstances that can affect their physical or psychological well- 
being. The way they deal with these situations can determine whether they surmount them or suffer a variety of undesirable consequences.

Cohen and Lazarus (1979) defined coping as the action-orientated and intrapsychic efforts to manage environments and internal demands, and conflicts among them, which tax or exceed a person's resources. Later, Lazarus and Folkman (1984) revised this definition to be the constantly changing cognitive and behavioral efforts to manage specific external and/or internal demands that are appraised as taxing or exceeding the resources of the person.

According to Hobfoll (1988), coping is one specific domain of activities for resisting the vicissitudes of stress. Moreover, the term coping in stress research refers to the set of behaviors we used in our efforts to manage stressful situations, regardless of whether such attempts are beneficial (Lazarus \& Folkman, 1984).

Different individuals use different coping strategies, inanition to that different problems lead individuals to use different coping strategies in different times. And according to Buettner et al., (1995), coping is a process that it changes over time. A person may use an emotion-focused strategy and then shift to a problem-focused strategy or vice versa.

A variety of idiosyncratic coping measures exists, but in recent years, researchers have typically used one of two instruments: the Ways of Coping measure (Folkman \& Lazarus, 1980) or the COPE (Carver, Scheier, \& Weintraub, 1989). Both of these two instruments focus on the two types of coping (problem-focus and emotion-focus). In addition, the COPE was developed and expanded from the way of coping, but it was classified as problem, emotion-focused or other ways of coping. Therefore, the researcher tried to concentrate on this method as being the latest one, but classified it into two problem and emotion focused only.

\subsection{Problem-Focused Coping}

Psychologies who study stress distinguish between coping strategies that are problem-focused and coping strategies that are emotion-focused. For the problem-focused coping, it involves taking steps to change the source of the stress, whereas emotion-focused coping involves efforts to change one's emotional response to the stressor.

Problem-Focused Coping is a rational approach that attempts to change the situation by changing either something in the environment or how the person interacts with the environment (Lazarus \& folkman, 1987). Therefore, it is very clear that this type of coping aimed at reducing the demands of the situation or expanding the resources for dealing with it. And it is clear that often used when the person believes that the demand is changeable.

According to psychologists, Problem-focused coping (take-charge strategies that deal with the problem at hand or eliminate the stressors through problem solving) often enhances feelings of control and reduces stress and its adverse consequences, assuming that the situation can be changed. Therefore, Researcher tried in this chapter to note the subtypes of problem focused-coping as Carver et al., (1989) divided it, and it was as follow:

\subsection{Emotion-focused coping}

Broad distinctions, such as problem-solving versus emotion-focused, have only limited utility for understanding coping, and so research on coping and its measurement has evolved to address a variety of more specific coping strategies. Emotion focused coping is used to manage all forms of emotional distress including feeling of depression, anxiety, frustration and anger. As discussed earlier, emotional distress usually compounds the problem of chronic pain (Hanson, 1997).

According to Zamble and Gekoski (1994), individual with emotion-focused coping style tend to make themselves feel better about a problematic situation without changing the problem itself or the perception of it. In contrast, individuals with problem-focused style tend to actually make changes on their situation or their perception of a situation in order to make it less or no longer stressful.

Research indicates that people use both types of strategies to combat most stressful events (Folkman \& Lazarus, 1980). The predominance of one type of strategy over another is determined, in part, by personal style (e.g., some people cope more actively than others) and also by the type of stressful event; for example, people typically employ problemfocused coping to deal with potential controllable problems such as work-related problems and family-related problems, whereas stressors perceived as less controllable, such as certain kinds of physical health problems, prompt more emotion-focused coping.

Broad distinctions, such as problem solving versus emotion-focused, have only limited utility for understanding coping, and so research on coping and its measurement has evolved to address a variety of more specific coping strategies. 


\section{The Impact of Both Types of Coping (Problem-Focused and Emotion-Focused Coping) on Well-Being}

A generalized beneficial effect of some activities of emotion-focused and problem focused coping such as instumental and emotional social support could occur because large social networks provide persons with regular positive experiences and a set of stable, socially rewarded roles in the community. This kind of support could be related to overall well-being because it provides positive affect, a sense of predictability and stability in one's life situation, and a recognition of self-worth. Integration in a social network may also help one to a void negative experiences (e.g., academic, economic or legal problems) that otherwise would increase the probability of psychological or physical disorder. This view of support has been conceptualized from a sociological perspective as "regularized social interaction" or "embeddedness" in roles (Cassel, 1976). And from a psychological perspective as social interaction, social integration, relational reward, or status support (e.g., Levinger \& Huesmann, 1980; Moos \& Moos, 1994; Reis, 2000).

Social support considered as one of the most important sub-types of problem- and emotion-focused coping. It could be related physical health outcomes through emotionally induced effects on neuroenducrine or immune system functioning (Jemmott \& Locke, 1984) or through influence on health-related behavioural patterns such as cigarette smoking, alcohol use, or medical help seeking (Krantz, Grunberg, \& Baum, 1985). In an extreme version, the main effect model postulates that an increase in social support will result in an increase in well being irrespective of the existing level of support. Furthermore, there is some evidence, however, that explained the main effect of support on major health outcomes for the contrast between persons who are essentially social isolates (i.e., those with very few or no social contacts) and persons with moderate or high level of support (House et al., 1988). Although the evidence is not conclusive, the suggestion is that there may be a minimum threshold of social contract required for an effect on mortality to be observed, with little improvement in health outcomes for levels of support above the threshold.

Social support may play a role at two different points in the causal chain linking stress to illness (Cohen, 1980; House, 1988). First, support may intervene between the stressful event (and expectation of that event) and stress reaction by attenuating or preventing a stress appraisal response. That is, the perception that others can and will provide necessary resources may redefine the potential for harm posed by a situation and/or bolster one's perceived ability to cope with imposed demands, and hence prevent a particular situation from being appraised as highly stressful. Second, adequate support may intervene between the experience of stress and the onset of the pathological outcome by reducing or eliminating the stress reaction or by directly influencing physiological processes. Support may alleviate the impact of stress appraisal by providing a solution to the problem, by reducing the perceived importance of the problem, by tranquilizing the neuroendocrine system so that people are less reactive to perceived stress, or by facilitating healthful behaviours (House, 1988).

Acceptance of the problem is very important in life, people have to accept their problems and take it as a challenge. A study done by Farhall and Gehrke's (1997), found that acceptance had the highest mean score of the coping sub-scales, followed by positive reinterpretation and growth and active coping. Acceptance was also the strongest factor in their research, only just failing to significantly predict hallucination control. Seeking social support for emotional reasons had the lowest mean score. This ought to be disturbing to health professionals who often perceive themselves as providers of emotional support. Participants in this project reported that they seldom sought emotional support, which perhaps relates to the stigma associated with stress. Interestingly, distress was positively associated with problemfocused coping. It may be that distress prompts people to attempt solving problems.

Study on emotion-focused styles of coping such as distancing, escape-avoidance and acceptance of responsibility were related to high levels of psychological distress in careers, confirming some earlier findings (Felton, Revenson, \& Henrichsen, 1984; Pruchno \& Nancy, 1989). Quayhagen and Quayhagen (1988), reported that fantasising (intrapsychic) was inversely associated with well being among patients. The use of emotion-focused coping strategies serves to avoid actually confronting the problem, and has been reported to show a positive association with depression and negative association with satisfactory outcome (Gass, \& Chag, 1989). However, the results from the present study are contrary to those reported by Pearlin and Schooler (1978), who found that strategies involving perceptual distortions of reality (e.g. intrapsychic) are adaptive, especially when the stressful situation was unavoidable. It could be possible that these discrepancies are related to the nature of the stressor being experienced

Early in this century, Sigmund Freud wrote about the deleterious effects of religion on psychological development and predicted that religion was an illusion that had no future. More recently, attorney Richard Yao founded a group named "Fundamentalists Anonymous" designed to help people overcome the so-called "emotional distress" of a conservative religious upbringing (Malony, 1995). Among this group are a counsellor Donald Slot, who titled his recent book "the dangers of growing up in Christian home," and California Clergyman named Book," who has appeared on a number of television talk shows warning the public about the bad effects of what he has termed "religious addiction" 
(Malony, 1995).

While the caution of Freud, Yao, Sloat, and Booth have been heard by many, the most vocal contender that religion is bad for mental health has been psychologist like Albert Ellis (1971), the founder of Rational Emotive Psychotherapy. Ellis, in a booklet entitled "the Case Against Religion," lists several aspects of religion which he feels keep people from becoming mentally healthy. These include his contentions that religion (i) makes people feel guilty and preoccupied with repentance when they should be accepting their humanness and getting on with life; (ii) encourages people to depend on God for direction when they should be autonomous and self-directed; (iii) indulges people's desire for certainty and predictability in life when they should be willing to live courageously with ambiguity and precariousness, and (iv) allows people to think that change come about by magical rituals rather than by logical reasoning and hard work (Malony, 1995).

A study done by Donahue (1995), found that there is a positive relationship between religion and both mental and physical health. In particular, regular religious practices (as opposed to specific beliefs) such as church or synagogue attendance, prayer and scripture reading, have been shown to be related to positive mental and physical health. In addition to that he suggested that religiously committed women who are battered suffer less severe symptoms than women without such commitment. However, his research also indicates that battered women attend religious services less frequently than maritally distressed controls.

\section{Conclusion}

Stress is a factor in the life of every person on Earth. The causes of stress range from the environment to genetics, with effects just as far reaching. It cannot be overstated that not all stress is harmful. Generally, chronic stress accounts for the greatest negative effects, both mentally and physically. Many theories have been put forth concerning stress and coping, however the overwhelming opinion of stress is that there is still much to learn. The foundation and processes connected to stress were not fully understood, which inhibits our knowledge of how and why stress affects human body as well as their thinking. Once the causes and effects of stress were fully understood, researcher would be able to more effectively manage and relieve it. In counclusion, stress and coping mechanisms goes together, but which method is the best to be used is depending on type of stress and individual needs. Based on the results of this study, a meditationbased stress reduction-counseling program can help and guide the person to know which coping method suite their needs.

\section{References}

Ashforth, B. \& Humphrey R., (1993). Emotional Labor in Service Roles: The Influence of Identity. Academy of Management Executive 18(1): 88115.

Baum, A., (1990). Stress, intrusive imagery, and chronic distress. Health psychology, 9, 653-675.

Benjamin, L., \& Walz, G.R. (1990). Counseling students and faculty for stress management. ASHE-ERIC Clearinghouse on Counseling and Personnel Services.

Bonner, K., (1967). Industrial implication of stress in L. Levi, (ed.) emotional stress. New Your: American Elsevier Publishing Co., 1967, $225-232$.

Buck, V.1972. Working Under pressure, London, Staples Press.

Buettner, H.M. et al., (1995). Kinetics of microtubule catastrophe assessed by probabilistic analysis. Biophys. J. 69, 796-802.

Caplan, R. D., (1983). Person-environment fit: Past, present, and future. In C. L. Cooper (Ed.), Stress research (pp. 35-78). New York: Wiley.

Carlesworth, E. A., \& Nathan, R. G. (1984). Stress management: A comprehensive guide to wellness. New York: Athenaeum.

Carver, C. S., Scheier, M. F., \& Weintraub, J. K., (1989). Assessing coping strategies: A theoretically based approach. Journal of Personality and Social Psychology, 56 (2): 267-283.

Cassel, J., (1976). The contribution of the social environment to host resistance. American Journal of Epidomology, 104: 107-123.

Cohen, F., \& Lazarus, R.S., (1979). Coping with thestress of illness, in Stone, C.G., Cohen, F., Adler, N.E., editors. Health psychology: A handbook. San Francisco: 217-254. CA: Jossey-Bass.

Cohen, S., (1980). After effects of stress on human performance and social behavior: A review of research and theory. Journal of psychological bulletin, 88: 82-108.

Cooper, C.L., \& Marshall, J., (1976). Occupational sources of stress: A review of the literature relating to coronary heart disease and mental health. Journal of Occupational Psychology, 1976, 49, 11 -28.

Cox, T. (1993). Stress research and stress management: Putting theory at work. HSE Contract Research Report, 25, London: HMSO.

Donahue, M. J., \& Benson P. L., (1995). Religion and the well-being of adolescents. Journal of Social Issues, 51 (2), 145-160.

Ellis, A., (1971). The case against religion: A psychotherapist's view. New York: Institute for Rational Living.

Farhall, J., \& Gehrke, M., (1997). Coping with hallucinations: exploring stress and coping frameworks. British Journal of Clinical Psychology, 36, 259-61.

Felton, B., Revenson, T., \& Henrichsen, G., (1984). Stress and coping in the explanation of psychological adjustment among chronically ill adults. Social Science and Medicine, 18, 889-898. 
Folkman, S., \& Lazarus, R. S. (1980). An analysis of coping in middle-aged community sample. Journal of health and social behavior, 21: 219239.

Folkman, S., \& Lazarus, R. S., (1985). If it changes it must be a process: A study of emotion and coping during three stages of a college examination. Journal of personality and social psychology; 48: 150-170.

Gass, K., and Chang, A., (1989). Appraisals of bereavement, coping, resources, and psychosocial health dysfunction in widows and widowers. Nurs Res, 38:31-36, 1989.

Hanson, P. G., (1986). The joy of stress. Fairway KS. Andrews McMeel \& Parker.

Hanson, R. K., (1997). The development of a brief actuarial risk scale for sexual offense recidivism. Ottawa, Ontario: Department of the Solicitor General of Canada. www.sgc.gc.ca.

Hobfoll, S. E., (1988). Stress, social support, and women. New York: A Member of the Taylor \& Francis Group.

House, J. S., Landies, K. R., \& Umberson, F., (1988). Social relationships and health. Science, 241: 540-550.

Jemmott, J. B., \& Locke S. E., (1984). Psychological factor, immunologic mediation, and human susceptibility to infectious diseases: how much do we know? Psychological Bulletin, 95, 78-108.

Jones, F. \& Bright, J., (2001). Stress: Myth, theory and research. New Jersey, US: Prentice Hall.

Kasl, S. V., (1978). Epidemiological contributions to the sutdy of work stress. In C. L. Cooper \& R. Pane (Eds.), Stress at work (pp. 3-48). Chichester: Wiley.

Kenneth M. et al., (1997). Humor as a stress moderator in the prediction of blood pressure obtained during five stressful tasks. Journal of Research in Personality 31, 523-542.

Krantz, D. S., Grunberg, N. E., \& Baum, A., (1985). Health psychology. Annual Review of Psychology, 36, 349-383.

Kugelmann, R. (1992). Stress: The nature and history of engineered grief. Westport: CT: Praeger.

Landy, F.J. \& Trumbo, D.A., (1976). Psychology of Work Behaviour. Homewood publication, Dorsey Press.

Lazarus, R. S., (1966). Psychological Stress and the Coping Process. NewYork: McGraw- Hill

Lazarus, R. S., et al, (1986). Dynamics of stressful Encounter: Cognitive Appraisal, coping, and encounter outcomes. Journal of Personality and Social Psychology, 50 (5): 992-1003.

Lazarus, R. S., Folkman, S., (1984). Stress, Ap- praisal and Coping. NewYork: Springer

Lazarus, R. S., Folkman, S., (1987). Transactional theory and research on emotions and coping. Eur. J. Personality 1:141-69.

Levinger, G., \& Huesmann, L. R., (1980). An "incremental exchange" perspective on the pair relationship: Interpersonal reward and level of involvement. In K. J. Gergen, M. S. Greenberg \& R. H. Willis (Eds.), Social exchange: advances in theory and research (pp. 165-196). New York: Plenum Press.

Maloney, P. R., (1995). ApJ, 447, L17 Pogge, R. W. 1989, ApJ, 345, 730.

Matheny, K. B., Aycock, D. W., Pugh, J. L., Curlette, W. L., \& Silva Cannella, K. A., (1986). Stress coping: A qualitative and quantita- tive synthesis with implications for treatment. The Counseling Psychologist, 14, 499-549.

McGrath, J., (1970). Social and Psychological Factors in Stress, New York: Holt, Rlne art, and Winston.

Microsoft Word [computer software]. (2000). Redmond, WA: Microsoft Corporation.

Mills M.R. (1982). Psychological Stress and Coping Techniques Among selected Elementary School Principals. Dissertation Abstract International, P.167.

Moos, R., \& Moos, B., (1994). Family environment scale manual: Development, applications, research (Third ed.). Palo Alto, CA: Consulting Psychologist Press.

National Health Ministries (2006). Stress \& The College Student. Retrieved December, 17, 2014, from: https://www.uic.edu/depts/ wellctr/docs/Stress\%20and\%20the\%20College\%20Student.pdf

Newton, T. (1995). Managing stress: Emotion and power at work. London: Sage.

Pearlin, L. I., \& Schooler, C., (1978). The structure of coping. Journal of Health and Social Behavior, 19, 2-21. doi:10.2307/2136319

Pestonjee, D. M. (1992). Stress and coping. New Delhi: Sage.

Pruchno, R. A. and Nancy L. R., (1989). "Husbands and Wives as Caregivers: Antecedents of Depression and Burden." The Gerontologist 29(2): 159-165.

Quayhagen M.P. \& Quayhagen M., (1988). Alzheimer's stress: Coping with the care giving role. Gerontologist. 28, 391-396.

Reis, H. T., \& Collins, N., (2000). Measuring relationship properties and interactions relevant to social support. In S. Cohen, L. G. Underwood \& B. Gottlieb (Eds.), Social support measurement and interventions: A guide for health and social scientists (pp. 136-194). New York: Oxford.

Rice PL. (1999). Stress and Health. 3rd Ed. USA: Brooks/Cole Publishing Company.

Sacchi, M., (2000), FX ARMA filters: 70th Annual International Meeting, SEG, Expanded Abstracts, 2092-2095.

Sandhu, B.K., et al., (1994). Factors relating to stress: Gaining control. In L. Murphy \& J. Hurrell \& S. Sauter \& G. Keita (Eds.). Job Stress Interventions. Washington, DC: American Psychological Association.

Selye, H., (1956). The stress of life. New York: McGraw Hill.

Selye, H., (1973). The evolution of the stress concept. Am. Sci, 61692-699.

Selye, H., (1974). Stress without distress. McClelland Stewart, Toronto.

Smith C. S., (1999). Organizational climate and occupational stressors as predictors of with- drawal behaviors and injuries in nurses. J Occup Organ Psychol 72:285-299.

Smith, P. J. (1990). Managing Stress a Guide to Asian living, Federal Publications (S) pte. Ltd, Singapore, pp:6-16 Turkington, C.A. (1998). Stress Management for Busy People. McGraw-Hill, New York, pg. 17-23.

Swept, B., \& Gmelch, W. H., (1977). Stress at the Desk and How to Cope Creatively. Oregon School Study Council, Vol. 21, No. 4, December 1977.

Zamble, E. \& Gekoski, W. L., (1994). Coping. In Ramachandron, V.S. (Ed.), Encyclopedia o f Human Behaviour (Vol.3). New York: Academic Press. 